\title{
Robotic surgery for rectal cancer as a platform to build on: review of current evidence
}

\author{
Pietro Achilli ${ }^{1}$ [ $\cdot$ Fabian Grass $^{1} \cdot$ David W. Larson $^{1}$
}

Received: 13 February 2020 / Accepted: 17 March 2020 / Published online: 4 May 2020

(c) Springer Nature Singapore Pte Ltd. 2020

\begin{abstract}
Laparoscopy in colorectal surgery reduces the rate of postoperative complications, shortens the length of stay in hospital, and improves the quality of patient care. Despite these established benefits, the technical challenges of rectal resection for cancer have resulted in most operations being performed through open surgery in the USA. Moreover, controversy in the current literature questions the oncologic safety of a laparoscopic approach for rectal cancer. How then can surgeons innovate to overcome the technical challenges while preserving the critical oncological outcomes of high-quality rectal cancer surgery? Robotics may be a platform that allows us to overcome the technical challenges in the pelvis while maintaining both oncological outcomes and the benefits of a minimally invasive technique. Current evidence suggests that the quality of total mesorectal excision, the rates of circumferential margin involvement, and postoperative outcomes are comparable between robotic and laparoscopic surgery. While a robotic approach demonstrates lower conversion rates and reduced surgeon workload, the operative time is longer and initial costs are higher; however, time and future science will determine its true benefits. We review the current state of robotic surgery and its impact on rectal cancer surgery.
\end{abstract}

Keywords Rectal cancer · Total mesorectal excision · Minimally invasive surgery $\cdot$ Robotic surgery $\cdot$ Robotic platform

\section{Introduction}

Laparoscopy has expanded rapidly in the field of colon surgery and is now considered the standard of care for elective colonic resections in well-resourced countries [1]. The laparoscopic benefits of better postoperative short-term outcomes including functional recovery, pain and use of narcotics, complications, and shorter hospital stay have driven this change [2,3]. Despite these obvious benefits, the use of laparoscopy for rectal cancer surgery is challenged. Technical difficulties, the need for extensive training, and cancer biology have contributed to stagnant implementation, with successful adoption only in high-volume centers in the USA [4]. Challenges related to the narrow anatomy of the pelvis and complex tumor morphologies, coupled with the limited nature of straight laparoscopic instruments, make tackling complex pelvic disease difficult.

Pietro Achilli

pietro.achilli89@gmail.com

1 Division of Colon and Rectal Surgery, Mayo Clinic Rochester MN, 200 First Street SW, Rochester, MN 55905, USA
Concerns about the oncologic safety of laparoscopic surgery (LS) for rectal cancer have been raised, according to several landmark randomized controlled trials (RCTs) comparing LS to open surgery (OS) $(9,10)$. The CLASICC trial demonstrated higher rates of circumferential resection margin (CRM) positivity (12\%) in LS than in OS (6\%) for anterior resection [5]. However, this difference has not impacted local recurrence or survival [6]. On a positive note, both the COLOR II and COREAN trials demonstrated no difference in CRM positivity and completeness of total mesorectal excision (TME) between the two groups and the long-term outcomes were comparable [7, 8]. All five RCTs demonstrated consistently good results for upper rectal cancer, although surgical outcomes for low rectal tumors need improvement [9]. Despite the apparent controversy, the basic facts for most surgeons in the field demonstrate a more rapid adoption of robotic approaches, which today seem to outpace LS [10]. Many surgeons, including the author group, believe that the proven short-term benefits of MIS and the longterm results of RCTs are proof enough to declare minimally invasive surgery (MIS) for rectal cancer safe and feasible in trained hands $[11,12]$. This review outlines the limits and benefits, both potential and demonstrated, of robotic 
surgery over a laparoscopic approach in the treatment of rectal cancer.

\section{Robotic surgery in the treatment of rectal cancer}

The robotic platform has been developed in an attempt to overcome the limitations of LS, while maintaining the advantages of MIS. Surgeons can improve their technical skills in laparoscopy, but the opportunity to leap forward as a platform has remained unchanged since the early 90 s. However, robotic surgery has innovated on its design providing potential new value in iterations of the platform since the FDA approved it in 2000. Today, the da Vinci Surgical System $^{\circledR}$ (Intuitive Surgical, Sunnyvale, CA, USA) is the prevailing system although there are new entrants to this market. The surgeon sits at a console with the potential benefit of three-dimensional high-definition vision. From the console, the surgeon navigates four arms (typically three instrumental and one endoscope) without the physical limits of straight-lined instruments or the stress of retraction pressure experienced in laparoscopic surgery. The wristed instruments have seven degrees of motion, allowing fluidity of movements and accuracy of dissection, especially in a narrow pelvis [13].

The first robotic TME was described in 2006 by Pigazzi et al. [14]; since then, many other case series have been published on the safety and feasibility of RS in the treatment of rectal cancer. The interest within the scientific surgical community, as demonstrated by the progressively growing number of publications per year, highlights the widespread adoption of this new technology. Likewise, the number of robotic cases in the USA now exceeds that of LS for rectal cancer and it is the only technique growing in popularity [15]. The ROLARR study, which assigned 471 patients to undergo either conventional laparoscopic or robotic-assisted resection, remains the only adequately powered RCT on RS for rectal cancer published in the literature [16]. This trial was powered to investigate conversion rates as a potential beneficial effect of RS and revealed a lower conversion rate in the RS group, although it did not reach significance $(8.1 \%$ vs. $12.2 \%)$. While male gender, high BMI, and low anterior resection were risk factors for conversion, the two approaches were comparable in terms of quality of resection, CRM positivity, and short-term postoperative outcomes. Although the ROLARR is considered the strongest available evidence comparing RS and LS, the results have been questioned because of the potentially confounding effect of the learning curve, which may have impacted the results [17].

Current studies (large retrospective series, smaller case series, and single-center reviews and meta-analyses) on RS for rectal cancer focus on a variety of endpoints including
CRM positivity, quality of TME, operative time, conversion rates, postoperative morbidity, length of stay, urologic and sexual functional recovery, surgeon workload, learning curve, and costs.

\section{Circumferential resection margin, quality of TME, and long-term outcomes}

The plane of surgery achieved during TME [graded as good (mesoretctal), intermediate (intramesorectal) and poor (muscularis propria plane)] and CRM involvement $(<1 \mathrm{~mm}$ between the deepest extent of tumor invasion into the mesorectal fat and the inked surface on the fixed specimen) are established surgical quality metrics and prognostic factors for local recurrence $[18,19]$. The ROLARR trial reported no significant difference in TME completion (poor TME: 9.3\% for RS and 5.2\% for LS) and CRM involvement (12\% for RS; $14 \%$ for LS) [16]. A recently published RCT from Korea comparing RS and LS showed comparable results for both outcomes ( $80.3 \%$ vs. $78.1 \%$ complete TME and $6.1 \%$ vs. 5.5\% CRM positivity) [20]. Slightly better results favoring RS in reducing CRM involvement were found in four recent large retrospective cohort studies [21-24] and in one prospective cohort study [25]; however, none achieved significance (Table 1). Completeness of TME was comparable between the two techniques in most series [26-30] (Fig. 1). Two recent meta-analyses confirm these findings $[31,32]$. Because of the limited history of RS for rectal cancer, there are few studies that report long-term outcomes. Two retrospective studies compared 3-year and 5-year overall survival and found similar rates in the RS and LS cohorts $[33,34]$.

\section{Operative time and conversion rate}

In the three largest single-center cohort studies comparing the operative times for RS and LS TME, two [23, 35] reported longer operative times for RS, while one showed no difference [24]. In two systematic reviews and meta-analyses including 2224 and 1074 patients, respectively, undergoing rectal resections, RS was associated with significantly longer operative times [31, 32]. Operative times for RS are affected by the time-consuming procedure of docking and instrument positioning. Our series evaluating the increased operative time required for RS, including our own learning curve of 260 robotic cases, demonstrated no increase in postoperative morbidity [36]. With time, experience, and innovations in the platform design (da Vinci $\mathrm{Xi}^{\circledR}$ ), the operative times are likely to decrease further [37,38].

Conversion to OS has a strong impact on both shortand long-term outcomes [39]. Hence, reducing conversion rates is of critical importance in MIS for rectal cancer. 
Table 1 Circumferential resection margin involvement and conversion rates

\begin{tabular}{|c|c|c|c|c|c|c|c|}
\hline \multirow[t]{2}{*}{ References } & \multirow[t]{2}{*}{ Year } & \multirow[t]{2}{*}{ Study design } & \multirow[t]{2}{*}{ Number of patients (RS/LS) } & \multicolumn{2}{|c|}{ Positive CRM, $n(\%)$} & \multicolumn{2}{|c|}{ Conversion rates, $n(\%)$} \\
\hline & & & & $\mathrm{RS}$ & LS & $\mathrm{RS}$ & LS \\
\hline Kang [37] & 2013 & Prospective cohort study & $165 / 165$ & $7(4.2)$ & $11(6.7)$ & $1(0.6)$ & $3(1.8)$ \\
\hline Speicher [52] & 2015 & $\begin{array}{l}\text { National } \\
\text { cancer database review }\end{array}$ & $956 / 5447$ & $45(5.5)$ & $231(4.9)$ & $91(9.5)$ & $951(17.5)^{*}$ \\
\hline Kim [35] & 2017 & Retrospective cohort study & $224 / 224$ & $9(4.0)$ & $11(4.9)$ & $0(0.0)$ & $2(0.9)$ \\
\hline Valverde [33] & 2017 & Retrospective cohort study & $65 / 65$ & $4(6)$ & $7(11)$ & $3(5)$ & $11(17)^{*}$ \\
\hline Jayne [28] & 2017 & RCT & $235 / 224230 / 236$ & $12(5.1)$ & $14(6.3)$ & $28(12.2)$ & $19(8.1)$ \\
\hline Rouanet [36] & 2018 & Retrospective cohort study & $200 / 200$ & $16(8)$ & $21(11)$ & $4(2.0)$ & $19(9.5)^{*}$ \\
\hline Kim [32] & 2018 & $\mathrm{RCT}$ & $66 / 73$ & $4(6.1)$ & $4(5.5)$ & $1(1.5)$ & $0(0.0)$ \\
\hline Crolla [47] & 2018 & Retrospective cohort study & $168 / 184$ & $8(4.8)$ & $4(2.2)$ & $3(1.8)$ & $23(12.5)^{*}$ \\
\hline Liu [34] & 2019 & Retrospective cohort study & $80 / 116$ & $0(0.0)$ & $1(1.0)$ & $1(0.8)$ & $4(3.5)$ \\
\hline
\end{tabular}

Recent RCTs and large cohort studies (> 50 patients per group) comparing robotic versus laparoscopic surgery for rectal cancer $C R M$ circumferential resection margin, $R C T$ randomized controlled trial, $R S$ robotic surgery, $L S$ laparoscopic surgery

*Significant difference between RS and LS $(p<0.05)$

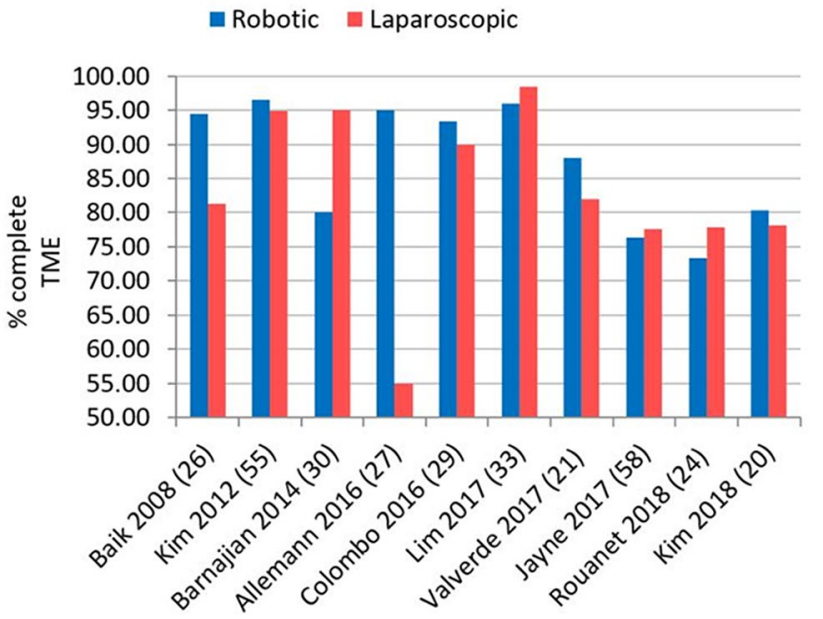

Fig. 1 Completeness of total mesorectal excision

Although the ROLARR trial failed to demonstrate a reduced risk of overall conversion for RS, significantly lower conversion rates were revealed in several subgroups, such as obese patients, men, and patients with low rectal cancer [16]. These results were confirmed by our institutional analysis, which revealed lower conversion rates in both obese and non-obese patients [40]. A National Cancer Database review of 16,275 patients undergoing robotic, laparoscopic, or open low anterior resection reported significantly lower conversion rates in the RS group [41]. The majority of large retrospective cohort series [20-24, 35, 41] and two recent meta-analyses [31, 32] confirmed these results (Table 1). Thus, RS seems to be associated with lower conversion rates than LS for rectal cancer.

\section{Postoperative morbidity and length of stay}

Numerous prospective and retrospective cohort studies have found no significant difference in postoperative complication rates or length of hospital stay between RS and LS patients [20-22, 32-42] (Table 2). These findings were confirmed by the ROLARR trial, where $32.4 \%$ of patients experienced some complication within 30 days: $31.7 \%$ in the conventional LS group and 33.1\% in the RS group [16]. Multiple meta-analyses have been conducted, but the results indicate no superiority of either technique in terms of postoperative short-term outcomes [31, 32, 42]. These results were challenged by our institutional series, which revealed significantly lower postoperative morbidity in the RS group (Crippa et al., Ann Surg 2020, in press).

\section{Technical considerations of splenic flexure mobilization}

Splenic iatrogenic injury during flexure mobilization occurs in approximately $0.4 \%$ of rectal resections and warrants total splenectomy in the majority of cases [43]. Given this nonnegligible morbidity, the necessity to routinely mobilize the splenic flexure remains controversial. Although some authors believe that splenic flexure mobilization is necessary to ensure a tension-free and well-vascularized anastomosis [44], most studies suggest that routine splenic flexure takedown does not confer any advantages in terms of postoperative morbidity and oncological outcomes among rectal cancer patients [45-47]. When splenic flexure mobilization is necessary, LS appears to be associated with a lower rate of incidental splenic procedures than OS [48]. While forced traction for adequate exposure during open 
Table 2 Postoperative morbidity and length of stay

\begin{tabular}{|c|c|c|c|c|c|c|c|}
\hline \multirow[t]{2}{*}{ References } & \multirow[t]{2}{*}{ Year } & \multirow[t]{2}{*}{ Study design } & \multirow[t]{2}{*}{$\begin{array}{l}\text { Number of } \\
\text { patients (RS/LS) }\end{array}$} & \multicolumn{2}{|c|}{$\begin{array}{l}\text { Postoperative complications, } \\
n(\%)\end{array}$} & \multicolumn{2}{|c|}{ Length of stay, mean (sd/range) } \\
\hline & & & & $\mathrm{RS}$ & LS & $\mathrm{RS}$ & LS \\
\hline Kang [37] & 2013 & Prospective cohort study & $165 / 165$ & $34(20.6)$ & $46(27.9)$ & $10.8(5.5)$ & $13.5(9.2)$ \\
\hline Speicher [52] & 2015 & $\begin{array}{l}\text { National } \\
\text { cancer database review }\end{array}$ & $956 / 5447$ & - & - & $5(4-7)$ & $5(4-7)$ \\
\hline Kim [35] & 2017 & Retrospective cohort study & $224 / 224$ & $77(34.3)$ & $56(25)$ & $13.5(14.1)$ & $13.8(10.9)$ \\
\hline Valverde [33] & 2017 & Retrospective cohort study & $65 / 65$ & $27(42)$ & $32(49)$ & $11( \pm 8)$ & $12( \pm 10)$ \\
\hline Jayne [28] & 2017 & $\mathrm{RCT}$ & $\begin{array}{l}236 / 230 \\
237 / 234\end{array}$ & $78(33.1)$ & $73(31.7)$ & $8.0(5.85)$ & $8.2(6.03)$ \\
\hline Rouanet [36] & 2018 & Retrospective cohort study & $200 / 200$ & $51(25.5)$ & $48(24.0)$ & $10(4-69)$ & $11(2-60)^{*}$ \\
\hline Kim [32] & 2018 & $\mathrm{RCT}$ & $66 / 73$ & $23(34.8)$ & $17(23.3)$ & $10.3(3.4)$ & $10.8(7.4)$ \\
\hline Crolla [47] & 2018 & Retrospective cohort study & $168 / 184$ & $71(42,2)$ & $111(60.3)$ & $6(2-67)$ & $7(3-104)$ \\
\hline Liu [34] & 2019 & Retrospective cohort study & $80 / 116$ & $6(7.5)$ & 24 (20.6) & $11.20(5.80)$ & $14.72(6.90)^{*}$ \\
\hline
\end{tabular}

Recent RCTs and large cohort studies (> 50 patients per group) comparing robotic versus laparoscopic surgery for rectal cancer

$C R M$ circumferential resection margin $R C T$ randomized controlled trial, $R S$ robotic surgery, $L S$ laparoscopic surgery

*Significant difference between RS and LS $(p<0.05)$

procedures represents the most important reason for iatrogenic injury, better and magnified visualization of the spleen and its attachments provided by the laparoscopic approach helps the surgeon avoid unnecessary traction [49].

RS provides similar advantages in terms of improved anatomic visualization leading to controlled traction. Recent studies suggest that through improved maneuverability conferred by the fourth-generation robotic platform, takedown of the splenic flexure can be efficiently performed and standardized [50, 51]. In our institution, the splenic flexure is addressed in a medial to lateral fashion, taking the inferior mesenteric vein at the inferior border of the pancreas, mobilizing the colonic mesentery off Gerota's fascia, entering the lesser sac above the pancreas, and continuing the mesenteric dissection along the inferior border of the pancreas to the splenic hilum. Once the medial dissection is complete, the lateral attachments are taken along with the disconnection of the omentum from the transverse colon.

\section{Urogenital function}

Sexual dysfunction after rectal cancer surgery occurs in up to $80 \%$ of men and $60 \%$ of women as a consequence of nerve damage during TME with the additional effect of preoperative radiation and psychological impairment in the presence of a stoma [52-54]. The magnified vision combined with increased precision and steadiness of movements through the robotic platform may facilitate better dissection of small anatomical structures such as the inferior hypogastric plexus [55]. Several small prospective and retrospective comparative studies demonstrated earlier recovery of normal voiding and sexual function after RS than after LS, particularly in men $[56,57]$. These results were confirmed more recently by a RCT [20] and a prospective propensity score-matched survey study [57]. Although not powered to answer these questions, both the ROLARR trial and the largest retrospective series to date have found no significant differences between the two groups in these specific outcomes [58]. Potential advantages of the robotic approach regarding genito-urinary functional recovery need further investigation through welldesigned studies and standardized functional assessments.

\section{Surgeon workload}

The surgeon must deal with the growing challenge of complex procedures in the setting of new treatment modalities, the need to master technical skills, and the economic pressure to achieve outstanding clinical results. Current evidence suggests a negative association between surgeon distress and clinical performance, potentially impacting the quality of care [59]. LS was introduced and promoted to improve patient care and less attention was paid to the impact of this new technology on surgeon workload and ergonomics [60]. In fact, both mental demand and physical effort experienced by surgeons are higher during LS than OS, especially when performing challenging procedures [61]. A recent study from Mayo evaluating a surgeon's perspective on open, laparoscopic, and robotic proctectomy demonstrated that robotic procedures required significantly less mental and physical effort, resulting in a reduced workload [62]. These results may be explained by the special design of the robotic platform, which combines both outstanding visuals and four arm 
controls within a single comfortable console. Future studies should assess if these surgeon-related benefits will translate into better clinical outcomes.

\section{Learning curve and costs}

It has been hypothesized that the advantages of the robotic platform regarding ease of use, improved range of motion, and better visualization may have an impact on the learning curve to acquire adequate surgical competence (16). The learning curve for robotic colorectal procedures is recognized to be multiphasic, with an initial training phase, followed by a second more stable progression phase, and finally by a consolidated third phase [63]. In a recent large cohort of robotic rectal resections, Sng et al., recommended at least 35 cases in the first phase, 93 cases in the second phase, and 69 cases in the third phase, with a mean operative time of $4.6 \mathrm{~h}$ [64]. Other studies have explored the learning curve of RS for rectal resections, reporting a range of 25-35 cases for the learning period $[28,65]$, although at least 40 cases were required to obtain sufficient expertise in previous papers that focused on the learning curve of LS $[65,66]$. Since laparoscopic experience plays an important role in proficiency in RS, comparing the learning curve between these two techniques could be difficult and the results should be interpreted with caution.

One of the prevailing arguments against acquisition of a robotic platform involves cost. Arguably, fixed costs related to the platform, including purchase and maintenance, inevitably demand an initial and sustained financial commitment [67]. However, several recent studies have revealed comparable expenses of OS, LS, and RS, taking into account intraoperative costs, costs of postoperative care, and duration of hospital stay. In particular, decreased conversion and postoperative complication rates, along with a shortened length of stay, may contribute to cost-efficacy [68, 69]. Furthermore, costs may decrease with surgical experience [70,71]. In rectal cancer surgery, it is particularly important to put surgery-related costs into perspective considering that the most significant cost drivers are chemo- and radiotherapies. Surgeons may harm themselves and their patients by railing against surgical tool innovation when that represents less than $5 \%$ of the total cost of care for a patient with rectal cancer in the USA.

\section{Conclusions}

RS for the treatment of rectal cancer appears to be oncologically safe and feasible with equal outcomes to other modes of surgery in both short-term morbidity and pathological surrogate markers of quality. Further research on both short- and long-term oncological outcomes is needed. The potential and demonstrated benefits of RS must be taken seriously as RS represents one of the few positively iterated platforms in surgery. Technical advantages over LS include improved three-dimensional vision, articulation of instruments, improved surgeon ergonomics, and better accessibility to narrow spaces such as the pelvis. Moreover, institutions like ours have demonstrated that these benefits lead to lower levels of mental and physical workload for the surgeon. As we view the landscape and trends in MIS surgery, surgeons are choosing Robotics as the "go-to" MIS approach for rectal cancer. These trends may be influenced by the findings of many institutional retrospective series, which demonstrate lower conversion rates and a shorter learning curve. While operative time and cost remain a challenge, one must remember the COST trial [72], in which the same arguments were made for LS. Today, those detracting voices for innovation have been drowned out by science and progress.

Future adequately designed and powered studies are needed to define the potential benefits of RS over LS. We are convinced that RS represents a platform to build on and one that is clearly demonstrating value for patients and surgeons.

\section{Compliance with ethical standards}

Conflict of interest Pietro Achilli and his co-authors have no conflicts of interest to declare.

\section{References}

1. Larson DW, Nelson H. Laparoscopic colectomy for cancer. J Gastrointest Surg. 2004;8(5):636-42.

2. Lacy AM, García-Valdecasas JC, Delgado S, Castells A, Taurá P, Piqué JM, et al. Laparoscopy-assisted colectomy versus open colectomy for treatment of non-metastatic colon cancer: a randomised trial. Lancet. 2002;359(9325):2224-9.

3. Larson DW, Davies MM, Dozois EJ, Cima RR, Piotrowicz K, Anderson $\mathrm{K}$, et al. Sexual function, body image, and quality of life after laparoscopic and open ileal pouch-anal anastomosis. Dis Colon Rectum. 2008;51(4):392-6.

4. Jiménez-Rodríguez RM, Rubio-Dorado-Manzanares M, DíazPavón JM, Reyes-Díaz ML, Vazquez-Monchul JM, GarciaCabrera AM, et al. Learning curve in robotic rectal cancer surgery: current state of affairs. Int J Colorectal Dis. 2016;31(12):1807-15.

5. Guillou PJ, Quirke P, Thorpe H, Walker J, Jayne DG, Smith AMH, et al. Short-term endpoints of conventional versus laparoscopicassisted surgery in patients with colorectal cancer (MRC CLASICC trial): multicentre randomised controlled trial. Lancet. 2005;365(9472):1718-26.

6. Green BL, Marshall HC, Collinson F, Quirke P, Guillou P, Jayne DG, et al. Long-term follow-up of the medical research council CLASICC trial of conventional versus laparoscopically assisted resection in colorectal cancer. Br J Surg. 2013;100(1):75-82.

7. van der Pas MH, Haglind E, Cuesta MA, Fürst A, Lacy AM, Hop WC, Bonjer HJ; COlorectal cancer Laparoscopic or Open Resection II (COLOR II) Study Group. Laparoscopic versus open 
surgery for rectal cancer (COLOR II): short-term outcomes of a randomised, phase 3 trial. Lancet Oncol. 2013;14(3):210-8. https ://doi.org/10.1016/S1470-2045(13)70016-0.

8. Jeong SY, Park JW, Nam BH, Kim S, Kang SB, Lim SB, et al. Open versus laparoscopic surgery for mid-rectal or low-rectal cancer after neoadjuvant chemoradiotherapy (COREAN trial): survival outcomes of an open-label, non-inferiority, randomised controlled trial. Lancet Oncol. 2014;15(7):767-74.

9. Mathis KL, Nelson H. Laparoscopic proctectomy for cancer. Ann Surg. 2019;269(4):603-4. https://doi.org/10.1097/SLA.00000 00000003211.

10. Damle A, Damle RN, Flahive JM, Schlussel AT, Davids JS, Sturrock PR, et al. Diffusion of technology: trends in robotic-assisted colorectal surgery. Am J Surg. 2017;214(5):820-4.

11. Fleshman J, Branda ME, Sargent DJ, Boller AM, George VV, Abbas MA, et al. Disease-free survival and local recurrence for laparoscopic resection compared with open resection of stage II to III rectal cancer: follow-up results of the ACOSOG Z6051 randomized controlled trial. Ann Surg. 2019;264(4):589-95.

12. Stevenson ARL, Solomon MJ, Brown CSB, Lumley JW, Hewett $\mathrm{P}$, Clouston $\mathrm{AD}$, et al. Disease-free survival and local recurrence after laparoscopic-assisted resection or open resection for rectal cancer: the Australasian laparoscopic cancer of the rectum randomized clinical trial. Ann Surg. 2019;269(4):596-602.

13. Elhage O, Challacombe B, Shortland A, Dasgupta P. An assessment of the physical impact of complex surgical tasks on surgeon errors and discomfort: a comparison between robot-assisted, laparoscopic and open approaches. BJU Int. 2015;115(2):274-81.

14. Pigazzi A, Ellenhorn JDI, Ballantyne GH, Paz IB. Roboticassisted laparoscopic low anterior resection with total mesorectal excision for rectal cancer. Surg Endosc Other Interv Tech. 2006;20(10):1521-5.

15. Stewart CL, Ituarte PHG, Melstrom KA, Warner SG, Melstrom LG, Lai LL, et al. Robotic surgery trends in general surgical oncology from the National inpatient sample. Surg Endosc. 2019;33(8):2591-601.

16. Jayne D, Pigazzi A, Marshall H, Croft J, Corrigan N, Copeland J, et al. 2017 Effect of Robotic-assisted vs conventional laparoscopic surgery on risk of conversion to open laparotomy among patients undergoing resection for rectal cancer: the ROLARR randomized clinical trial. JAMA. 2017/10/27. Department of academic surgery, Leeds institute of biological and clinical sciences, university of Leeds, Leeds, UK. Department of surgery, university of California, Irvine. Clinical trials research unit, Leeds institute of clinical trials res. 318:1569-80. Available from: https://www.ncbi. nlm.nih.gov/pubmed/29067426https://jamanetwork.com/journals/ jama/articlepdf/2658320/jama_Jayne_2017_oi_170064.pdf

17. Corrigan N, Marshall H, Croft J, Copeland J, Jayne D, Brown J 2018 Exploring and adjusting for potential learning effects in ROLARR: a randomised controlled trial comparing roboticassisted vs. standard laparoscopic surgery for rectal cancer resection. Trials 2018/06/28. Clinical trials research unit, Leeds institute of clinical trials research, university of Leeds, Leeds, LS2 9JT, UK.n.corrigan@leeds.ac.uk. Clinical trials research unit, Leeds institute of clinical trials research, university of Leeds, Leeds, LS2 9JT, U. 19:339. Available from: https://www.ncbi. nlm.nih.gov/pubmed/29945673https://www.ncbi.nlm.nih.gov/ pmc/articles/PMC6020359/pdf/13063_2018_Article_2726.pdf

18. Quirke P, Steele R, Monson J, Grieve R, Khanna S, Couture J, et al. Effect of the plane of surgery achieved on local recurrence in patients with operable rectal cancer: a prospective study using data from the MRC CR07 and NCIC-CTG CO16 randomised clinical trial. Lancet. 2009;373:821-8.

19. Nagtegaal ID, Quirke P. What is the role for the circumferential margin in the modern treatment of rectal cancer? J Clin Oncol. 2008;26:303-12.
20. Kim MJ, Park SC, Park JW, Chang HJ, Kim DY, Nam BH, et al. Robot-assisted versus laparoscopic surgery for rectal cancer: a phase II open label prospective randomized controlled trial. Ann Surg. 2018;267(2):243-51.

21. Valverde A, Goasguen N, Oberlin O, Svrcek M, Fléjou JF, Sezeur A, et al. Robotic versus laparoscopic rectal resection for sphinctersaving surgery: pathological and short-term outcomes in a singlecenter analysis of 130 consecutive patients. Surg Endosc Springer USA. 2017;31:4085-91.

22. Kim HJ, Choi GS, Park JS, Park SY, Lee HJ, Woo IT, et al. 2018 Selective lateral pelvic lymph node dissection: a comparative study of the robotic versus laparoscopic approach. Surg Endosc 32:2466-73. Available from: https://dx.doi.org/10.1007/s0046 4-017-5948-4

23. Kim J, Baek SJ, Kang DW, Roh YE, Lee JW, Kwak HD, et al. Robotic resection is a good prognostic factor in rectal cancer compared with laparoscopic resection: long-term survival analysis using propensity score matching. Dis Colon Rectum. 2017;60(3):266-73.

24. Rouanet P, Bertrand MM, Jarlier M, Mourregot A, Traore D, Taoum C, et al. 2018 Robotic versus laparoscopic total mesorectal excision for sphincter-saving surgery: results of a singlecenter series of 400 consecutive patients and perspectives. Ann Surg Oncol. 2018/09/02. Surgical Oncology Department, Institut du Cancer de Montpellier (ICM), Univ Montpellier, Montpellier, France. philippe.rouanet@icm.unicancer.fr. Surgical Oncology Department, Institut du Cancer de Montpellier (ICM), Univ Montpellier, Montpellier, France. 25:3572-9. Available from: https:// www.ncbi.nlm.nih.gov/pubmed/30171509https://link.springer. com/content/pdf/10.1245\%2Fs10434-018-6738-5.pdf

25. Kang J, Yoon KJ, Min BS, Hur H, Baik SH, Kim NK, et al. The impact of robotic surgery for mid and low rectal cancer. Ann Surg. 2013;257(1):95-101.

26. Baik SH, Ko YT, Kang CM, Lee WJ, Kim NK, Sohn SK, et al. Robotic tumor-specific mesorectal excision of rectal cancer: shortterm outcome of a pilot randomized trial. Surg Endosc Other Interv Tech. 2008;22(7):1601-8.

27. Allemann P, Duvoisin C, Di Mare L, Hübner M, Demartines N, Hahnloser D. Robotic-assisted surgery improves the quality of total mesorectal excision for rectal cancer compared to laparoscopy: results of a case-controlled analysis. World J Surg. 2016;40(4):1010-6.

28. Kim HJ, Choi GS, Park JS, Park SY. Multidimensional analysis of the learning curve for robotic total mesorectal excision for rectal cancer: lessons from a single surgeon's experience. Dis Colon Rectum. 2014;57(9):1066-74.

29. Colombo PE, Bertrand MM, Alline M, Boulay E, Mourregot A, Carrère $S$, et al. Robotic versus laparoscopic total mesorectal excision (TME) for sphincter-saving surgery: is there any difference in the transanal TME rectal approach? A single-center series of 120 consecutive patients. Ann Surg Oncol. 2016;23(5):1594-600.

30. Barnajian M, Pettet D, Kazi E, Foppa C, Bergamaschi R. Quality of total mesorectal excision and depth of circumferential resection margin in rectal cancer: a matched comparison of the first 20 robotic cases. Color Dis. 2014;16(8):603-9.

31. Prete FP, Pezzolla A, Prete F, Testini M, Marzaioli R, Patriti A, et al. Robotic versus laparoscopic minimally invasive surgery for rectal cancer: a systematic review and meta-analysis of randomized controlled trials. Ann Surg. 2018;267(6):1034-46.

32. Li X, Wang T, Yao L, Hu L, Jin P, Guo T, Yang K. The safety and effectiveness of robot-assisted versus laparoscopic TME in patients with rectal cancer: A meta-analysis and systematic review. Medicine (Baltimore). 2017;96(29):e7585. https://doi. org/10.1097/MD.0000000000007585.

33. Lim DR, Bae SU, Hur H, Min BS, Baik SH, Lee KY, et al. Longterm oncological outcomes of robotic versus laparoscopic total 
mesorectal excision of mid-low rectal cancer following neoadjuvant chemoradiation therapy. Surg Endosc. 2017;31(4):1728-37.

34. Park SY, Choi GS, Park JS, Kim HJ, Ryuk JP. Short-term clinical outcome of robot-assisted intersphincteric resection for low rectal cancer: a retrospective comparison with conventional laparoscopy. Surg Endosc. 2013;27(1):48-55.

35. Crolla R, Mulder PG, van der Schelling GP. Does robotic rectal cancer surgery improve the results of experienced laparoscopic surgeons? An observational single institution study comparing 168 robotic assisted with 184 laparoscopic rectal resections. Surg Endosc. 2018/05/16. Department of Surgery, Amphia Breda, Breda, The Netherlands. rcrolla@ amphia.nl. Consulting Biostatistician, Amphia Academy, Amphia Breda, Breda, The Netherlands. Department of Surgery, Amphia Breda, Breda, The Netherlands.; 2018; Available from: https://www.ncbi.nlm.nih.gov/pubme d/29761276https://link.springer.com/content/pdf/10.1007\%2Fs00 464-018-6209-x.pdf

36. Duchalais E, Machairas N, Kelley SR, Landmann RG, Merchea A, Colibaseanu DT, et al. Does prolonged operative time impact postoperative morbidity in patients undergoing robotic-assisted rectal resection for cancer? Surg Endosc. 2018/03/17. Division of Colon and Rectal Surgery, Mayo Clinic, 200 First Street SW, Rochester, MN, 55905, USA. Division of Colon \& Rectal Surgery, Mayo Clinic, 4500 San Pablo Road, Jacksonville, FL, 32224, USA. Division of Colon and Rectal Surgery, Mayo Clinic, 200 F; 2018; Available from: https://www.ncbi.nlm.nih.gov/pubme d/29546672https://link.springer.com/content/pdf/10.1007\%2Fs00 464-018-6098-z.pdf

37. Morelli L, Di Franco G, Guadagni S, Rossi L, Palmeri M, Furbetta N, et al. Robot-assisted total mesorectal excision for rectal cancer: case-matched comparison of short-term surgical and functional outcomes between the da Vinci Xi and Si. Surg Endosc. 2018;32(2):589-600.

38. Morelli L, Guadagni S, Di Franco G, Palmeri M, Caprili G, D'Isidoro $\mathrm{C}$, et al. Use of the new da Vinci $\mathrm{Xi}{ }^{\circledR}$ during robotic rectal resection for cancer: a pilot matched-case comparison with the da Vinci $\mathrm{Si}^{\circledR}$. Int J Med Robot Comput Assist Surg. 2017;13(1):e1728.

39. Gouvas N, Georgiou PA, Agalianos C, Tzovaras G, Tekkis P, Xynos E 2018. Does conversion to open of laparoscopically attempted rectal cancer cases affect short- and long-term outcomes? A systematic review and meta-analysis. J Laparoendosc Adv Surg Tech A [Internet]. 2017/06/02. 1 Department of Colorectal Surgery, Worcestershire Acute Hospitals NHS Trust, Worcester, United Kingdom . 2 Department of Surgery and Cancer, Imperial College, Chelsea and Westminster Campus, London, United Kingdom . 3 The 2nd Department of General Surg 28:117-26. Available from: https://www.ncbi.nlm.nih.gov/pubme d/28570140https://www.liebertpub.com/doi/pdfplus/10.1089/ lap. 2017.0112

40. Crippa J, Grass F, Achilli P, Mathis KL, Kelley SR, Merchea A, Colibaseanu DT, Larson DW. Risk factors for conversion in laparoscopic and robotic rectal cancer surgery. Br J Surg. 2020;107(5):560-6. https://doi.org/10.1002/bjs.11435.

41. Speicher PJ, Englum BR, Ganapathi AM, Nussbaum DP, Mantyh CR, Migaly J. Robotic low anterior resection for rectal cancer: A national perspective on short-term oncologic outcomes. Ann Surg. 2015;262:1040-5.

42. Sun Y, Xu H, Li Z, Han J, Song W, Wang J, et al. Robotic versus laparoscopic low anterior resection for rectal cancer: a metaanalysis. World J Surg Oncol. 2016;14(1):61.

43. Masoomi H, Carmichael JC, Mills S, Ketana N, Dolich MO, Stamos MJ. Predictive factors of splenic injury in colorectal surgery: data from the Nationwide Inpatient Sample, 2006-2008. Arch Surg. 2012;147(4):324-9. https://doi.org/10.1001/archs urg.2011.1010.
44. Shorthouse A. Splenic flexure mobilisation for anterior resection performed for sigmoid and rectal cancer. Ann R Coll Surg Engl. 2008;90(8):638-42.

45. Brennan DJ, Moynagh M, Brannigan AE, Gleeson F, Rowland M, O'Connell PR. Routine mobilization of the splenic flexure is not necessary during anterior resection for rectal cancer. Dis Colon Rectum. 2007;50(3):302-7.

46. Katory M, Tang CL, Koh WL, Fook-Chong SMC, Loi TT, Ooi BS, et al. A 6-year review of surgical morbidity and oncological outcome after high anterior resection for colorectal malignancy with and without splenic flexure mobilization. Color Dis. 2008;10(2):165-9.

47. Marsden MR, Conti JA, Zeidan S, Flashman KG, Khan JS, Leary DPO, et al. 2011 The selective use of splenic flexure mobilization is safe in both laparoscopic and open anterior resections. Colorectal Dis. 2012;14(10):1255-61. https://doi. org/10.1111/j.1463-1318.2011.02927.x.

48. Isik O, Aytac E, Ashburn J, Ozuner G, Remzi F, Costedio M, et al. Does laparoscopy reduce splenic injuries during colorectal resections? An assessment from the ACS-NSQIP database. Surg Endosc Springer New York LLC. 2015;29:1039-44.

49. Isik O, Sapci I, Aytac E, Snyder K, Stocchi L, Kessler H, et al. 2018 Laparoscopy reduces iatrogenic splenic injuries during colorectal surgery. Tech Coloproctol [Internet]. Springer International Publishing 22:767-71 Available from: https://dx.doi. org/10.1007/s10151-018-1861-7

50. Liang JT, Huang J, Chen TC. Standardize the surgical technique and clarify the relevant anatomic concept for complete mobilization of colonic splenic flexure using da vinci $\mathrm{xi}^{\circledR}$ robotic system. World J Surg Springer New York LLC. 2019;43:1129-36.

51. Isik O, Benlice C, Gorgun E. A novel approach for robotic mobilization of the splenic flexure. Tech Coloproctol SpringerVerl Ital s.r.1. 2017;21:53-7.

52. Lange MM, Marijnen CAM, Maas CP, Putter H, Rutten HJ, Stiggelbout AM, et al. Risk factors for sexual dysfunction after rectal cancer treatment. Eur J Cancer. 2009;45(9):1578-88.

53. Banerjee AK. Sexual dysfunction after surgery for rectal cancer. Lancet. 1999;353(9168):1900-2.

54. Hendren SK, O'Connor BI, Liu M, Asano T, Cohen Z, Swallow CJ, et al. Prevalence of male and female sexual dysfunction is high following surgery for rectal cancer. Ann Surg. $2005 ; 242(2): 212$.

55. Kim JY, Kim NK, Lee KY, Hur H, Min BS, Kim JH. A comparative study of voiding and sexual function after total mesorectal excision with autonomic nerve preservation for rectal cancer: Laparoscopic versus robotic surgery. Ann Surg Oncol. 2012;19(8):2485-93.

56. D'Annibale A, Pernazza G, Monsellato I, Pende V, Lucandri G, Mazzocchi P, et al. Total mesorectal excision: a comparison of oncological and functional outcomes between robotic and laparoscopic surgery for rectal cancer. Surg Endosc. 2013;27(6):1887-955.

57. Kim HJ, Choi GS, Park JS, Park SY, Yang CS, Lee HJ. The impact of robotic surgery on quality of life, urinary and sexual function following total mesorectal excision for rectal cancer: a propensity score-matched analysis with laparoscopic surgery. Color Dis. 2018;20(5):O103-O113113.

58. Jayne D, Pigazzi A, Marshall H, Croft J, Corrigan N, Copeland $\mathrm{J}$, et al. Effect of robotic-assisted vs conventional laparoscopic surgery on risk of conversion to open laparotomy among patients undergoing resection for rectal cancer the rolarr randomized clinical trial. JAMA J Am Med Assoc. 2017;318(16):1569-80.

59. Shanafelt TD, Balch CM, Bechamps G, Russell T, Dyrbye L, Satele D, et al. Burnout and medical errors among American surgeons. Ann Surg. 2010;251(6):995-1000. 
60. Park A, Lee G, Seagull FJ, Meenaghan N, Dexter D. Patients benefit while surgeons suffer: an impending epidemic. J Am Coll Surg. 2010;210(3):306-13.

61. Berguer R, Smith WD, Chung YH. Performing laparoscopic surgery is significantly more stressful for the surgeon than open surgery. Surg Endosc. 2001;15(10):1204-7.

62. Law KE, Lowndes BR, Kelley SR, Blocker RC, Larson DW, Hallbeck MS, Nelson H. NASA-task load index differentiates surgical approach: opportunities for improvement in colon and rectal surgery. Ann Surg. 2020;271(5):906-12. https://doi.org/10.1097/ SLA.0000000000003173.

63. Pernar LIM, Robertson FC, Tavakkoli A, Sheu EG, Brooks DC, Smink DS. An appraisal of the learning curve in robotic general surgery. Surg Endosc. 2017;31(11):4583-96.

64. Sng KK, Hara M, Shin JW, Yoo BE, Yang KS, Kim SH. The multiphasic learning curve for robot-assisted rectal surgery. Surg Endosc. 2013;27(9):3297-307.

65. Yamaguchi T, Kinugasa Y, Shiomi A, Sato S, Yamakawa Y, Kagawa $\mathrm{H}$, et al. Learning curve for robotic-assisted surgery for rectal cancer: use of the cumulative sum method. Surg Endosc. 2015;29(7):1679-85.

66. Park IJ, Choi GS, Kang BM, Lim KH, Lee IT, Jeon SW, et al. Comparison of one-stage managements of obstructing left-sided colon and rectal cancer: stent-laparoscopic approach vs. intraoperative colonic lavage. J Gastrointest Surg. 2009;13(5):960-5.

67. Tandogdu Z, Vale L, Fraser C, Ramsay C. A systematic review of economic evaluations of the use of robotic assisted laparoscopy in surgery compared with open or laparoscopic surgery. Appl Health Econ Health Policy. 2015;13(5):457-67.

68. Ielpo B, Duran H, Diaz E, Fabra I, Caruso R, Malavé L, et al. Robotic versus laparoscopic surgery for rectal cancer: a comparative study of clinical outcomes and costs. Int J Colorectal Dis. 2017;32(10):1423-9.

69. Cleary RK, Mullard AJ, Ferraro J, Regenbogen SE. The cost of conversion in robotic and laparoscopic colorectal surgery. Surg Endosc. 2018;32(3):1515-24.

70. M L, G S, L V, DF G, C L, P M, et al. Robot-assisted versus laparoscopic rectal resection for cancer in a single surgeon's experience: a cost analysis covering the initial 50 robotic cases with the da Vinci Si. Int J Colorectal Dis. 2016;31(9):1639-48.

71. Byrn JC, Hrabe JE, Charlton ME. An initial experience with 85 consecutive robotic-assisted rectal dissections: improved operating times and lower costs with experience. Surg Endosc. 2014;28(11):3101-7.

72. Nelson H, Sargent DJ, Wieand HS, Fleshman J, Anvari M, Stryker SJ, et al. A Comparison of laparoscopically assisted and open colectomy for colon cancer. N Engl J Med. 2004;350:2050-9.

Publisher's Note Springer Nature remains neutral with regard to jurisdictional claims in published maps and institutional affiliations. 